\title{
A Multiple Myxoma in Right Ventricle and Right Atrium
}

\author{
SAMSUN NAHAR, HELAL UDDIN , FATEMA BEGUM, MOMENUZZAMAN, K N KHAN
}

Department of Cardiology, United Hospital Limited (UHL), Dhaka.

Address for Correspondence: Dr. Samsun Nahar, Specialist Cardiologist, Department of cardiology, United Hospital Limited, Dhaka; E-mail: snahar.moni@gmail.com.

\begin{abstract}
:
We are reporting a case of multiple myxoma in right atrium and right ventricle in a 55 years male. Dignosis of myxomas were incidental when he was under evaluation for heart failure.Diagnosis was done by both echocardiography and CT scan of chest. Myxomas originating from the right ventricle and right atrium are even less common and can present unusual diagnostic and therapeutic challenges.
\end{abstract}

University Heart Journal 2017; 13(1): 33-35

\section{Introduction}

Cardiac myxomas are the commonest primary cardiac tumours. They are infrequently multiple and rarely multifocal. The usual site of occurrence of myxomas is LA ( $75 \%)$, RA ( $15 \%$ to $20 \%$ ), and left and right ventricle ( $3 \%$ to $4 \%$ each). ${ }^{1}$ Multiple myxomas and rare locations are more common in familial disease. ${ }^{2}$ Sporadic myxomas arising in different cardiac chambers have been rarely reported. Myxomas arising from the right ventricle and right atrium are extremely rare ${ }^{3-5}$.

We report a case of myxoma located in right atrium and right ventricle.

\section{Case summary}

A 55yrs old gentleman admitted in UHL with the complaints of shortness of breath, leg swelling, weight loss .He had a history of old MI (2003) and CABG(2003) .Clinical examination revealed, he is anemic, icteric and odematous, JVP-raised . A cardiac evaluation showed regular heart rhythm with resting HR -100 beats per minute, BP-90/6o mmHg, diminished heart sounds, (3/ 6) systolic murmur at the left upper sternal border (which did not change with position or respiration), and also at apex which radiate towards axilla . Other clinical findings were liver -palpable,tender on palpation, creps present in lung bases .

The results of routine blood tests: $\mathrm{Hb} \%-11.1 \mathrm{gm} / \mathrm{dl}$, erythrocyte sedimentation rate $(24 \mathrm{~mm} / \mathrm{h})$, S.creatinine $-1.18 \mathrm{mg} / \mathrm{dl}$, S.bilirubin $-4.1 \mathrm{mg} / \mathrm{dl}$, SGPT-125 U/L.USG of abdomen showed features suggestive of congestive cardiac failure. His coagulation profile was normal and duplex study of both lower limb revealed no evidence of DVT. His ECG-revealed RVH with strain. Doppler echocardiography showed multiple myxomas(globular shaped mobile mass) one in right atrium $(3.8 \times 3.5 \mathrm{~mm})$ and two in RV apex $(3.2 \times 1.8 \mathrm{~mm} \mathrm{\&} 0.8 \times 0.9 \mathrm{~mm}$ respectively),akinetic inferior, mid-basal inferolateral and mid-basal anterolateral walls, LVEF-20\%. There was no RVOT obstruction and right sided inflow velocity was normal. There mitral and tricuspid regurgitation was grade-III and calculated PASP was $65 \mathrm{mmHg}$. CT scan of heart showed heart is enlarged in size with dilated chambers, well defined mildly enhancing hypodense lesions measuring $4.17 \times 4.52 \times 4.46 \mathrm{~cm}$ in right atrium. $3.21 \times 2.65 \times 3.29 \mathrm{~cm} \& 1.22 \times 1.28 \times 1.27 \mathrm{~cm}$ in apical region of $\mathrm{RV}$ which are suggestive of myxoma in RA \& RV.
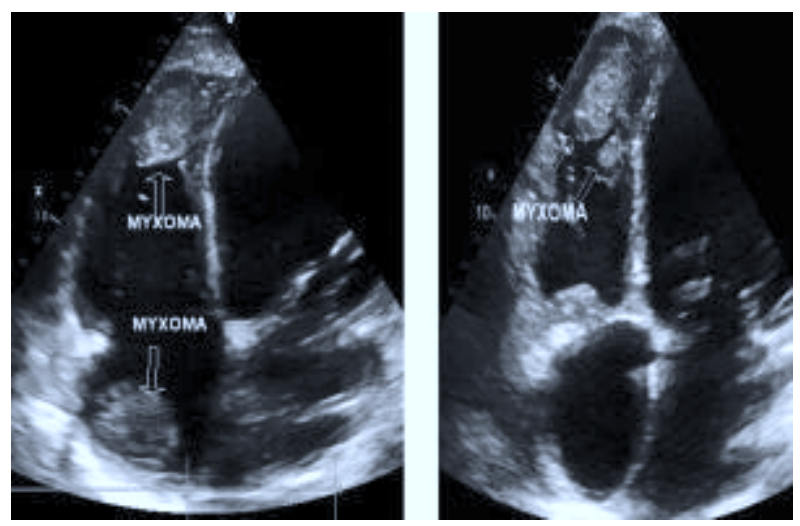

Fig-1:Apical 4 chamber view showed myxoma in $R A, R V$ 

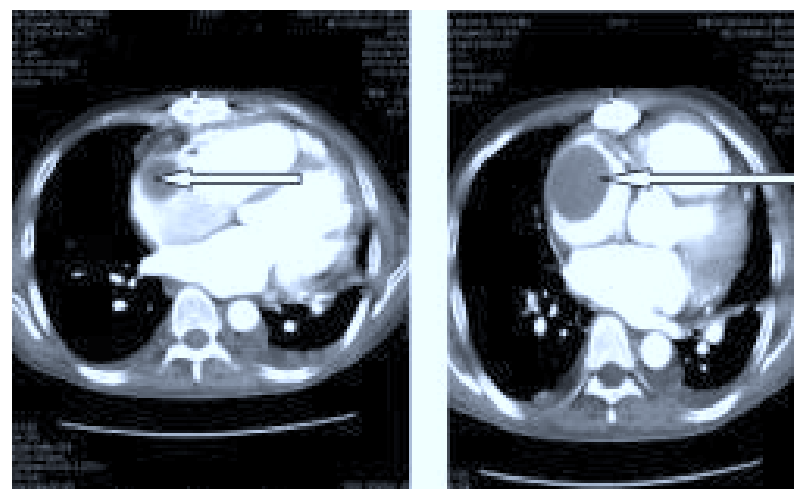

Fig-2:CT scan of heart showed hypodense masses within right chamber of heart

\section{Discussion:}

Intracardiac myxoma is the most common tumor of the heart (incidence estimated about 0.5 cases per million people per year), usually they are lobulated single masses presenting as pedunculated left or right atrial tumour developing from Fossa Ovalis area of inter-atrial septum. ${ }^{3}$ Occasionally these neoplasms are multiple in one or more cardiac chambers. ${ }^{6}$ But our cases right atrial myxoma arises from the free wall of right atrium. Reports of myxomas arising from the right ventricle are extremely rare and up to now only few cases have been reported in the literature.

On a macroscopic level, typical myxomas are pedunculated and gelatinous in consistency; the surface may be smooth, villous, or friable. Tumors vary widely in size, ranging from 1 to $15 \mathrm{~cm}$ in diameter, and weighing between 15 and $180 \mathrm{~g}$. About 35 percent of myxomas are friable or villous, and these tend to present with emboli. Larger tumors are more likely to have a smooth surface and to be associated with cardiovascular symptoms. ${ }^{7}$

Clinical symptoms of myxomas depend on its position and size, are atypical and vary to a large extent in terms of general symptoms, heart symptoms and embolic events. Commonly observed symptoms and signs are dyspnea, orthopnea, paroxysmal nocturnal dyspnea, pulmonary edema, cough, hemoptysis, edema, and fatigue. Symptoms may be worsened in certain body positions, due to motion of the tumor within the atrium. On physical examination, a characteristic"tumor plop" may be heard early in diastole .Constitutional symptoms (e.g., fever, weight loss) are seen in around 30 percent of patients. Laboratory abnormalities (e.g., anemia and elevations in the erythrocyte sedimentation rate, $\mathrm{C}$ reactive protein, or globulin level) are present. ${ }^{8,9}$
Screening for myxoma is important in cases of family history, in complex myxoma, or Carney disease. Our patient present with the feature of right heart failure and the diagnosis was made by echocardiography.

Transthoracic Echocardiography (TTE) is simple and usually can identify a tumor; Transesophageal Echocardiography (TEE) may be more informative. Although both cardiac MRI and ultrafast CT provide noninvasive, high resolution images of the heart, MRI generally is preferred. In addition to furnishing detailed anatomic images, the T1- and T2-weighted sequences reflect the chemical microenvironment within a tumor, thereby offering clues as to the type of tumor that is present. However, CT scanning is still useful when MRI is not immediately available or is contraindicated 10,11 .

Once a presumptive diagnosis of myxoma has been made on imaging studies, prompt resection is required because of the risk of embolization or cardiovascular complications, including sudden death. ${ }^{12}$ Surgical excision of right ventricular myxomas must be accomplished as soon as possible after the diagnosis has been established to prevent serious complications such are valvular obstruction, pulmonary embolization and syncope. ${ }^{13}$ Surgical intervention offers the cure for patients with sporadic intracardiac myxomas. Familial myxomas have greater tendency to recur, even many years after the operation. Although only several cases of recurrence of the right ventricular myxoma have been reported so far ${ }^{14,15}$ routine echocardiography control after the operation is advised.

\section{Conclusion:}

We report this case of multiple myxomas in right side of the heart (right atrium and right ventricle) which is a rare entity. Transthoracic echocardiography is enough to diagnose such a case. We can do CT scan of heart to further evaluate about specific location of myxomas. The presented case illustrates the usefulness of CT scan both in diagnosing and planning surgical approach in patients with the myxomas. While diagnosis of this case was easily accomplished by echocardiogram, cardiac CT scan greatly aided in the accurate diagnosis and we feel it should be a part of routine pre-operative evaluation of patients with cardiac myxoma.

\section{Limitation}

Although we know that histological findings of myxoma is gold standard test to diagnose myxoma, it was not possible because of patients disagree for surgical management. 


\section{References:}

1. Attar S, Lee YC, Singleton R, Scherlis L, David R, McLaughlin JS. Cardiac myxoma. Ann Thorac Surg. 1980; 29:397-405.

2. Reynen K. Cardiac myxomas. N Engl J Med. 1995; 333:1610-17.

3. Gonzalez A, Altieri PI, Marquez EU, Cox RA, Castillo M. Massive pulmonary embolism associated with a right ventricular myxoma. Am J Med 1980; 69(5): 795-8.

4. Bortolotti U, Mazzucco A, Valfre C, Valente M, Pennelli N, Gallucci V. Right ventricular myxoma: Review of the literature and report of two patients. Ann Thorac Surg 1982; 33(3): 277-84

5. Karagounis A, Sarasam M. Myxoma of free wall of the right ventricle: a case report. J Card Surg 2005; 20(1): 73-6.

6. Prichard RW .Tumors of the heart-review of the subject and report of 150 cases.Arch .Pathol.1951;SI :98-128.

7. Anderson ST,Pitt A, et al. A case of biatrial myxomas with successful surgical removal .J.Thorac. Cardiovas.Surg.1970;59:786.

8. Pinede L ,Duhaut P,Loire R .Clinical presentation of left atrial myxoma. A series of 112 consecutive cases .Medicine (Baltimore).2001;80:159.

9. Kolluru A, Desai D, Cohen GI. The etiology of atrial myxoma tumor plop. J Am Coll Cardiol. 2011;57(21):e371.

10. Aggarwal SK, Barik R, Sarma TC, Iyer VR, Sai V, Mishra J, Voleti $\mathrm{CD}$. Clinical presentation and investigation findings in cardiac myxomas: new insights from the developing world. Am Heart J. 2007;154(6):1102-07.

11. Schroeder S, Achenbach S, Bengel F, Burgstahler C, Cademartiri F, de Feyter P, George R, et al. Cardiac computed tomography: indications, applications, limitations, and training requirements: report of a Writing Group deployed by the Working Group Nuclear Cardiology and Cardiac CT of the European Society of Cardiology and the European Council of Nuclear Cardiology. Eur Heart J. 2008;29(4):531-56

12. Rahmanian PB, Castillo JG, Sanz J, Adams DH, Filsoufi F. Cardiac myxoma: preoperative diagnosis using a multimodal imaging approach and surgical outcome in a large contemporary series. Interact Cardiovasc Thorac Surg. 2007;6(4):479-83.

13. Cohena R, Singhb G, Menab D, Christine A, Mirrer B . Atrial myxoma: a case presentation and review. Cardiol Res • 2012;3(1): 41-44.

14. Kirüanski BO, Mikiü A, Velinovic M. Right ventricular myxoma-A case report. Vojnosanit Pregl 2013; 70(6): 609-611.

15. Segal OR, Robinson NM, Timmis AD. Images in cardiology: recurrent myxoma of the right ventricle. Heart 2000; 84(6): 652.

16. Keeling IM, Oberwalder P, Anelli-Monti M, Schuchlenz H, Demel U, Tilz GP, et al. Cardiac myxomas: 24 years of experience in 49 patients. Eur J Cardiothorac Surg 2002; 22(6): 971-7. 